\title{
Tuber size variation and organ preformation constrain growth responses of a spring geophyte
}

Received: 22 December 2004 / Accepted: 20 September 2005 / Published online: 25 October 2005

(C) Springer-Verlag 2005

\begin{abstract}
Functional responses to environmental variation do not only depend on the genetic potential of a species to express different trait values, but can also be limited by characteristics, such as the timing of organ (pre-) formation, aboveground longevity or the presence of a storage organ. In this experiment we tested to what degree variation in tuber size and organ preformation constrain the responsiveness to environmental quality and whether responsiveness is modified by the availability of stored resources by exposing the spring geophyte Bunium bulbocastanum to different light and nutrient regimes. Growth and biomass partitioning were affected by initial tuber size and resource availability. On average, tuber weight amounted to $60 \%$, but never less than $30 \%$ of the total plant biomass. Initial tuber size, considered an estimate of the total carbon pool available at the onset of treatments, affected plant growth and reproduction throughout the experiment but had little effect on the responsiveness of plants to the treatments. The responsiveness was partly constrained by organ preformation: in the second year variation of leaf number was considerably larger than in the first year of the treatments. The results indicate that a spring geophyte with organ preformation has only limited possibilities to respond to short-term fluctuations of the environment, as all leaves and the inflorescence are preformed in the previous growing season and resources stored in tubers are predominantly used for survival during dormancy and are not invested into plastic adjustments to environmental quality. Such spring geophytes have only limited possibilities to buffer environmental variation.
\end{abstract}

Communicated by Christian Koerner

M. J. A. Werger $(\bowtie) \cdot$ H. Huber

Department of Plant Ecology, Utrecht University,

P.O. Box 80084, 3508 TB Utrecht, The Netherlands

E-mail: m.j.a.werger@bio.uu.nl

H. Huber

Department of Ecology, Radboud University Nijmegen,

Toernooiveld 1, 6525 ED Nijmegen, The Netherlands
This explains their restriction to habitats characterized by predictable changes of the environmental conditions.

Keywords Biomass partitioning - Life history strategy · Light · Nutrient - Organ preformation - Storage ·

Tuber size

\section{Introduction}

Functional responses to more or less predictable environmental variation are of vital importance for plant performance, survival and reproduction. They may occur on an evolutionary and/or ecological time scale. On the one hand, predictable seasonal variation in habitat conditions has prompted the evolution of life histories that are characterized by a precise temporal match between plant development and the annual pattern of resource availability (Billings and Mooney 1968). On the other hand, phenotypic plasticity allows plants to finetune their morphology and development to small-scale, unpredictable variation in resource availability and other environmental conditions (Schlichting and Pigliucci 1998; Pigliucci 2001; de Kroon et al. 2005).

A wide range of natural habitats worldwide are characterized by a short annual period of favorable growth conditions. Conspicuous examples include strong seasonal patterns of temperature in arctic-alpine habitats (Körner 2003; Onipchenko 2004), the pattern of light availability in deciduous forest understories (Salisbury 1925; Packham and Harding 1982; Werger and van Laar 1985) and the pattern of water availability in Mediterranean (Beard 1983; Orshan 1989) and (semi-) desert habitats (von Willert et al. 1992). Such environments often harbor plants with life histories that enable them to make optimal use of the narrow window in time that is available for growth and reproduction, surviving the relatively long and unfavorable period in a dormant state (perennials) or as seeds (annuals).

A common life history feature of plants employing temporal escape strategies is an early and rapid devel- 
opmental startup after environmentally induced resting periods. Spring geophytes and other ephemeral perennial herbs from temperate deciduous forests, for instance, develop belowground storage organs and preform their leaves and reproductive structures in the previous growing season to allow for such a quick start (Whigham 1974; Sohn and Policansky 1977; Inouye 1986; Zimmerman and Whigham 1992; Geber et al. 1997a, b; Wijensinghe and Whigham 1997; Wyka 1999, 2000; Kleijn et al. 2005). Their stored reserves enable them to quickly flush their preformed leaves at a time when their potential competitors and the canopy trees are still inactive. Storage of reserves as well as preformation of organs constitute carry-over effects in which environmental conditions of the previous year affect future growth and performance of plants (Chapin et al. 1990; Geber et al. 1997a).

Stored reserves allow plants to buffer the negative impact of environmental fluctuations and facilitate plant survival in years with a negative resource balance (Zimmerman and Whigham 1992; Suzuki and Stuefer 1999). Phenotypic plasticity is a potentially alternative strategy to using stored reserves for buffering temporarily low resource availability, as environmentally inducible changes in morphology and biomass partitioning can also alleviate transient resource shortage (Elemans 2005). Resource storage and plasticity may not be independent components of plant survival strategies, as the expression of morphological plasticity is likely to cause considerable carbon costs (Huber et al. 1998), which could be provided by stored reserves. However, the preformation of plant structures may impose developmental constraints on the expression of plasticity and may slow down, postpone or prevent direct responses of plant organs to environmental conditions (Aydelotte and Diggle 1997; Diggle 1997; Geber et al. 1997a; Worley and Harder 1999; Huber et al. 2004). To date we have only a limited understanding of the interplay between stored reserves, organ preformation and a plant's response to environmental resource availability. This study aims at contributing to a better insight in how these interactions shape patterns of phenotypic plasticity in morphology, growth and biomass partitioning in an ephemeral perennial plant from temperate environments.

To this end we analyzed the annual growth and biomass partitioning patterns of the spring geophyte Bunium bulbocastanum L., and we studied the flexibility (i.e., plasticity) of biomass production and biomass allocation in response to variation in light and nutrient availability to test the following hypotheses: (1) The size of the storage organ at the beginning of the growing season is positively related to a plant's ability to cope with poor resource conditions. This effect may be due to the reallocation of stored carbohydrates to the expression of plastic changes in the size or structure of resource-capturing organs, or by the use of stored resources to maintain growth and reproduction. (2) These growth-promoting effects of the storage organ should be stronger in resource-poor as compared to resource-rich conditions. In poor conditions, initial tuber size variation should therefore have a stronger effect on final tuber mass than in rich conditions. (3) Organ preformation constrains the annual growth pattern and the expression of plastic responses to the environment. Therefore, we expect little variation in leaf numbers and inflorescence production in response to resource availability. Effects of resource conditions on vegetative growth and flowering are likely to be delayed by organ preformation, implying that the environmental triggers (e.g., resource availability) and the solicited plant response are not synchronized.

\section{Material and methods}

\section{Model species}

The perennial tuber-forming Bunium bulbocastanum $\mathrm{L}$. (Apiaceae) was used for this study. B. bulbocastanum originates from the Mediterranean (Meusel et al. 1978). Its short and early growing season enabled $B$. bulbocastanum to spread as a weed in arable fields over large parts of Central Europe. According to historical accounts the species occurred frequently and abundantly in extensively managed arable fields and in vineyards all over Central and Southern Europe (Mössler 1833; Hegi 1975). Due to intensified agricultural practices $B$. bulbocastanum has become a rare species in most of Central Europe.

Seeds of $B$. bulbocastanum germinate in early spring and produce a single cotyledon and a root system. Seedlings start to produce a tuber at an early stage of development (Rauh 1950; Irmisch 1854). One-year-old seedlings do not usually produce foliar leaves (except for plants in exceptionally favorable growing conditions). From the second year onward, plants produce rosette leaves between the end of February and mid-March. Flowering typically starts in the third year of life. All aboveground structures and roots wither in June or early July. A dead flower stalk may stay loosely connected to the tuber during summer until physical disturbance (e.g., caused by wind or small mammals) separates the stalk from the tuber.

The tubers are the only perennating organs of this species. In late summer one small bud is visible on the tuber, which contains a number of preformed rosette leaves and in the case of flower-induced individuals, an inflorescence that will emerge in the subsequent spring (H. Huber, personal observation). Root growth starts in late autumn. Inflorescences emerge in late spring and peak flowering coincides with the senescence of the rosette leaves (for more details on the species see Rauh 1950; Irmisch 1854; Huber et al. 1996). B. bulbocastanum reproduces sexually only.

\section{Experiment}

Seeds of B. bulbocastanum were collected in a chalk grassland located on a former arable field in the south- 
ernmost part of The Netherlands (Wrakelberg, South Limburg; Bobbink and Willems 1987; Willems and Bobbink 1990). In the following spring (and after a period of cold stratification in the field), the seeds were germinated and the plants were grown under uniform conditions in the botanical garden of Utrecht University for 2 years. After the second growing season, in October, the tubers were carefully washed free of soil, weighed and randomly allocated to one of six treatments. The fresh weight of the tubers ranged from 370 to $1,710 \mathrm{mg}$ at the beginning of the experiment. Plants were potted in individual pots with a volume of approximately 1.51 . River sand was used as a substrate.

The plants were subjected to two light treatments. Plants growing under high light conditions were exposed to full daylight, while plants in low light conditions experienced $20 \%$ of ambient PPFD. Shading was imposed by means of a black, spectrally neutral shade cloth. Plants growing under high light conditions were subjected to four levels of nutrient availability. These were obtained by adding Hoagland solution with an equivalent of $100,50,25$ and $12.5 \mathrm{~kg} \mathrm{~N}^{-1}$ year $^{-1}$, respectively. Plants grown under low light conditions were grown at nutrient concentrations equivalent to 100 and $25 \mathrm{~kg} \mathrm{~N} \mathrm{ha}^{-1}$ year $^{-1}$. Plants were fertilized once a month throughout the growing period.

Monthly harvests started in early March and were carried out until July in the third year of the experiment. One additional harvest was carried out in April of the fourth growing season to get an indication of the longerterm impact of the treatments on growth characteristics, and to be able to assess the fate of tubers during winter dormancy. The number of replicates ranged from 7 to 10 plants per harvest per treatment, with a total number of 270 plants for the whole experiment. At each harvest, plants were separated into roots, tubers, leaves, stems and umbels (including flowers and seeds). Leaves were divided into petioles and lamina and the area of the lamina was measured with a LiCor 3100 leaf area meter (LiCor, NE, USA). All plant parts were dried to constant mass at $72^{\circ} \mathrm{C}$ and weighed.

The results of the experiment were analyzed with a three-way analysis of covariance. Type III sum of squares were calculated to correct for unequal sample sizes. Light availability, nutrient availability and harvest time were used as main fixed factors and the fresh weight of tubers at the beginning of the experiment was used as a covariate. In a second analysis the interactions between the covariate and the three main effects were included in the model in order to test the hypothesis that initial tuber weight affects the pattern of growth and the response to treatments. We performed a regression analysis to test for direct effects of initial tuber weight on growth and morphology, using initial weight as predictor variable and the residuals of several traits after correcting for the effect of light and nutrient availability as the dependent variable. This analysis was performed for each harvest and each trait separately, in order to assess the duration of carry-over effects from initial tuber size.

\section{Results}

\section{Biomass production}

Light availability, nutrient availability and harvest time significantly affected the total biomass production as well as the dry weight of all plant components (Table 1, Fig. 1). Total plant weight increased steadily during the growing period and reached its maximum in June (Fig. 1). Light and nutrient availability had positive effects on total biomass (Table 1, Fig. 1). The positive nutrient effect was more pronounced in high light as compared to low light conditions (see Table 1: significant Light $\times$ Nutrient interaction as well as significant Light $\times$ Nutrient $\times$ Harvest interaction). After 3 years of growth, total plant biomass increased only in plants raised under high light and high nutrient conditions (compare April harvests of the third and fourth year).

Tuber biomass was the largest single contributor to total biomass (Fig. 1). As a consequence, the pattern of total dry matter accumulation followed closely the pattern of tuber weight. Tuber weight increased until June, after which it started to drop. Tuber weights measured in April of the fourth growing season were up to $60 \%$ lower than those recorded in July of the third year. This biomass loss was more pronounced under low light (54 $50 \%$ ) than in high light conditions $(12-40 \%)$. At the beginning of the fourth growing season tubers of unshaded plants were 3-7 times larger than tubers at the beginning of the third growing season. In low light conditions, the tubers did not show any net gain of biomass within 1 year. Tuber weights of plants in full daylight increased significantly faster if they received high nutrient concentrations (Fig. 1, Table 1). Roots were significantly heavier under high than in low light conditions (Fig. 1, Table 1). Nutrient availability did not affect root biomass.

\section{Effects of initial tuber weight}

The initial size of the tuber had significant effects on all measured plant traits except for specific leaf area (SLA) and relative allocation to tubers (Table 1,2). This effect was strongest for total plant and tuber weights, followed by root weight, leaf weight, relative allocation to leaves and weight of the reproductive structures (Table 1). The significant interaction term between the initial weight of tubers and the three main effects (Table $1, \mathrm{H}^{*} \mathrm{COV}$ ) revealed that initial tuber weight affected growth during the experiment. Initially larger tubers gave rise to plants whose biomass increased faster than in plants originating from initially smaller tubers. There was also a significant interaction between the light availability and initial tuber weight, indicating that the response of plants to shading depended on their initial tuber weight. The response of inflorescence biomass to light and 
Table 1 Effects of light availability (L), nutrient availability (N), harvest time $(\mathrm{H})$ and initial weight (Cov) on biomass accumulation and leaf characteristics. The table gives $F$ values of a three-way analysis of covariance and their significances. Values in the second line (represented in italics) show the $F$ values and their significances if the interaction terms between the covariate and the three main effects are included in the model

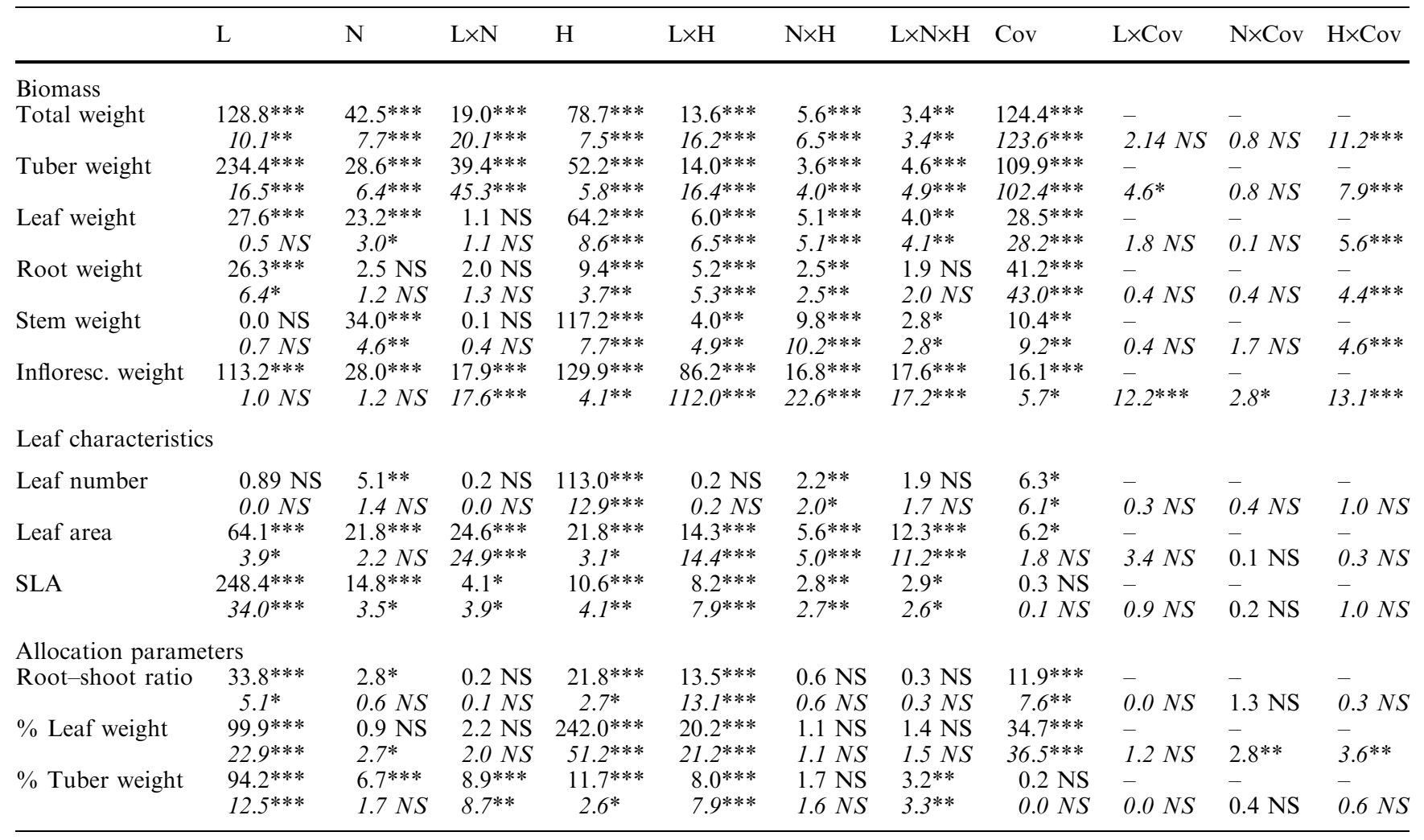

Significance levels are as follows: $* * * P<0.001, * * P<0.01, * P<0.05$, NS $P>0.05$

nutrient availabilities was also significantly affected by initial tuber weight (Table 1).

The effects of initial tuber size on plant traits changed throughout the growing period (Fig. 2, Table 2). In early spring there was a tight correlation between the initial tuber weight and the weight of different plant organs (Fig. 2, Table 2). These relationships loosened over the course of the experiment indicating that initial tuber weight became a progressively weaker predictor of plant development and performance. In March of the third year, $87 \%$ of the variation in tuber weight could be attributed to variation in initial tuber weight (after accounting for light and nutrient effects; Table 2). In April of the fourth year, this value had dropped to $17 \%$. The predictive value of initial tuber mass for root and leaf weight decreased from $66 \%$ to $1 \%$ and from $50 \%$ to $4 \%$, respectively. Initial tuber weight also explained up to $26 \%$ of the variation in stem weight and up to $38 \%$ of the variation in inflorescence weight (Table 2). Initial tuber weight had only marginal effects on leaf traits, such as SLA, leaf number and leaf area (Table 2).

\section{Reproduction}

All plants reproduced sexually. The onset of stem growth tended to be delayed under low as compared to high light conditions (data not shown). Inflorescencebearing stems started to appear in April and May and were present until the end of the growing season in July (Fig. 1, Table 1). Stem weight was positively affected by nutrient availability, irrespective of light conditions (Fig. 1, Table 1). Inflorescences, including umbels, flowers and seeds, started to grow in June and their weight peaked in July (Fig. 1). In contrast to stem weight, inflorescence weight was significantly higher when plants received high as compared to low light availabilities, irrespective of nutrient conditions (Fig. 1, Table 1). Plants in full daylight and high nutrient treatment produced the heaviest inflorescences (Fig. 1, Table 1).

\section{Leaf traits}

Rosette leaves continued to unfold until the beginning of April. Total leaf number increased further in May with the appearance of leaves situated on inflorescencebearing stems (Fig. 3). Rosette leaves started to die back in May (data not shown) and stem leaves withered in June. In July most leaves had disappeared (Fig. 3). The number of leaves showed hardly any response to the light treatments (Fig. 3, Table 1). 
Fig. 1 Effects of light and nutrient availability on the seasonal growth and biomass increment on plants and their components. For significances of the effect of light and nutrient availabilities and harvest time, see Table 1. Symbols used in graphs: triangles $\mathrm{N} 100$, squares $\mathrm{N} 50$, circles N25, crosses N12. Open symbols high light, closed symbols low light
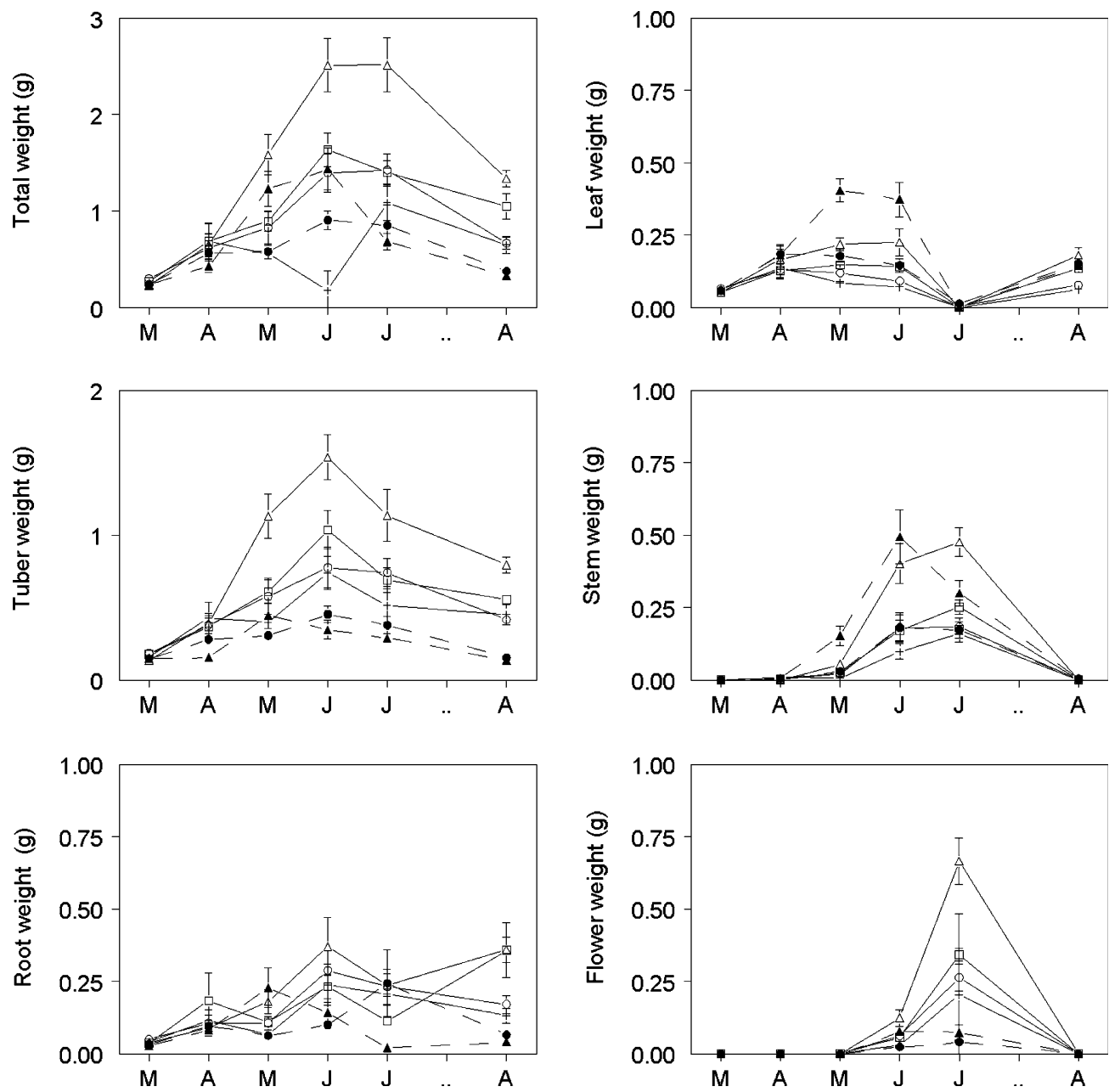

Leaf area development followed a similar trajectory as the seasonal pattern of leaf weights (Figs. 1, 3). Total leaf area was significantly affected by light and nutrient conditions. Shading resulted in the production of larger leaves as compared to high light conditions (Fig. 3, Table 1). Within light levels nutrient availability was positively related to leaf area (Fig. 3, Table 1). Plants grown in low light and high nutrient conditions showed a remarkable increase in the total leaf area during May and June (4-8 times higher than in any other treatment; Fig. 3).

Plants produced heavier leaves under high as compared to low nutrient availability, irrespective of light availability (Fig. 1, Table 1). Plants subjected to low light and high nutrient availability allocated most resources to leaves, followed by plants subjected to high light and high nutrient availability (Fig. 4, Table 1). With the exception of shaded plants subjected to high nutrient availability the SLA showed little variation throughout the growing season (Fig. 3, Table 1). Shaded plants grown under high nutrient conditions produced the thinnest leaves, followed by shaded plants in nutrient-poor conditions, followed by plants subjected to full daylight (Fig. 3, Table 1).
Biomass allocation patterns

Root-shoot allocation was calculated as the biomass investment to roots (excluding tubers) divided by the biomass investment to all aboveground structures. Under high light conditions significantly more biomass was allocated to roots than to shoots (Fig. 4). During the third growing season root-shoot ratios remained relatively constant, while they changed dramatically at the beginning of the fourth growing season. Plants exposed to high light conditions showed a sudden increase of the relative allocation to roots at that time (Fig. 1). Plants allocated $30-70 \%$ of their total biomass to tubers, with high light plants allocating significantly more to tubers than shaded plants (Fig. 4). In plants subjected to low light conditions and high nutrient availability relative allocation to tubers steadily decreased from April to June. In plants under high light conditions, allocation to tubers decreased only in July, coinciding with seed production.

\section{Discussion}

This experiment revealed complex interactive effects of tuber size and environmental quality on growth and 
Table 2 The effects of initial weight on biomass accumulation and leaf traits throughout the experiment after correcting for the effects of light and nutrient availability. For the regression analysis initial tuber weight was the predictor variable and the residuals of plant traits, obtained by a two-way analysis of variance with light and nutrient as the main effects, the dependent variables. In the table regression coefficients and their significance levels are presented. Values in the second line (in italics) show the $r^{2}$ of fit of the regression model

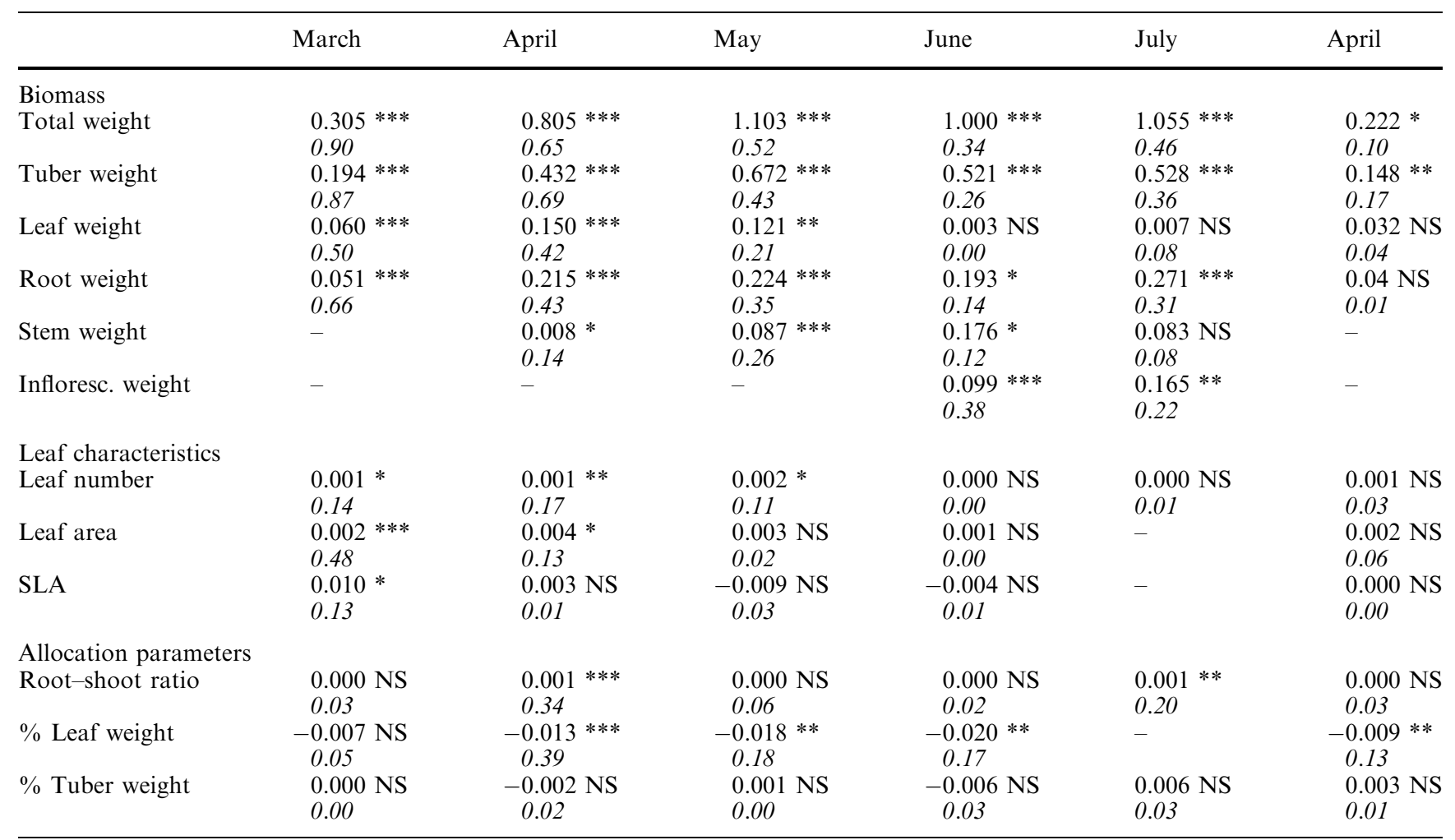

Significance levels are as follows: $* * * P<0.001,{ }^{* *} P<0.01,{ }^{*} P<0.05$, NS $P>0.05$

reproduction in the geophyte $B$. bulbocastanum. While the amount of resources stored in the tuber had an important effect on growth and reproduction, it hardly affected the response of plants to environmental quality. This experiment provides clear evidence for delayed effects of environmental quality on leaf traits and biomass allocation patterns, suggesting a potentially significant role of organ preformation for constraining plant responsiveness to environmental quality. The results also show that $B$. bulbocastanum has adopted a dual life strategy composed of typical elements of polycarpic perennials and monocarpic annuals, in which the relative importance of the strategy elements is environment-dependent.

\section{Role of the tuber}

Initial tuber size strongly affected plant growth and the size of different plant components, while this correlation decayed in an environment-specific manner over time. Especially in plants growing under more favorable conditions, the effect of initial tuber size was soon overridden by current growth. Initial tuber size had only a weak effect on the biomass of reproductive structures, indicating that the primary role of the perennating storage organ is to ensure survival during the long unfavorable period and that flowering and seed production is mainly realized by resources captured in the same growing season. This strategy seems remarkable considering that inflorescences are initiated in the previous year.

Throughout the growing season $30-70 \%$ of a plant's biomass was allocated to tubers, reflecting the importance of the storage organ for the life history and survival strategy of $B$. bulbocastanum. The important function of storage is to keep up respiration during dormancy, thereby allowing the plant to survive during prolonged unfavorable periods which have to be bridged in a vegetative resting phase (Othen and Wehrmeyer 2004). This function is clearly shown by a dramatic depletion of the resources stored in the tuber during winter. Depending on light treatments, the average tuber weight decreased by $12-60 \%$ between the end of the third, and the beginning of the fourth growing season. Wyka (1999) has also reported large decreases (up to $50 \%$ ) in the amount of stored carbohydrates in $O x y$ tropis sericea during winter.

The tuber appeared to contribute only a relatively small amount of carbohydrates for plant growth in lightlimited environments (Figs. 1, 4). This is in clear contrast to the prediction that stored resources may be used 
Fig. 2 Effect of initial tuber weight on plant size and tuber weight throughout the experiment. The $x$ axis gives the initial tuber weight; the $y$ axis gives the residuals for total biomass and tuber weight after correcting for the effects of light and nutrient conditions. $\mathrm{H} 1-\mathrm{H} 6$ indicate the successive harvests (see Material and methods). For significances and strength of associations, see Table 2
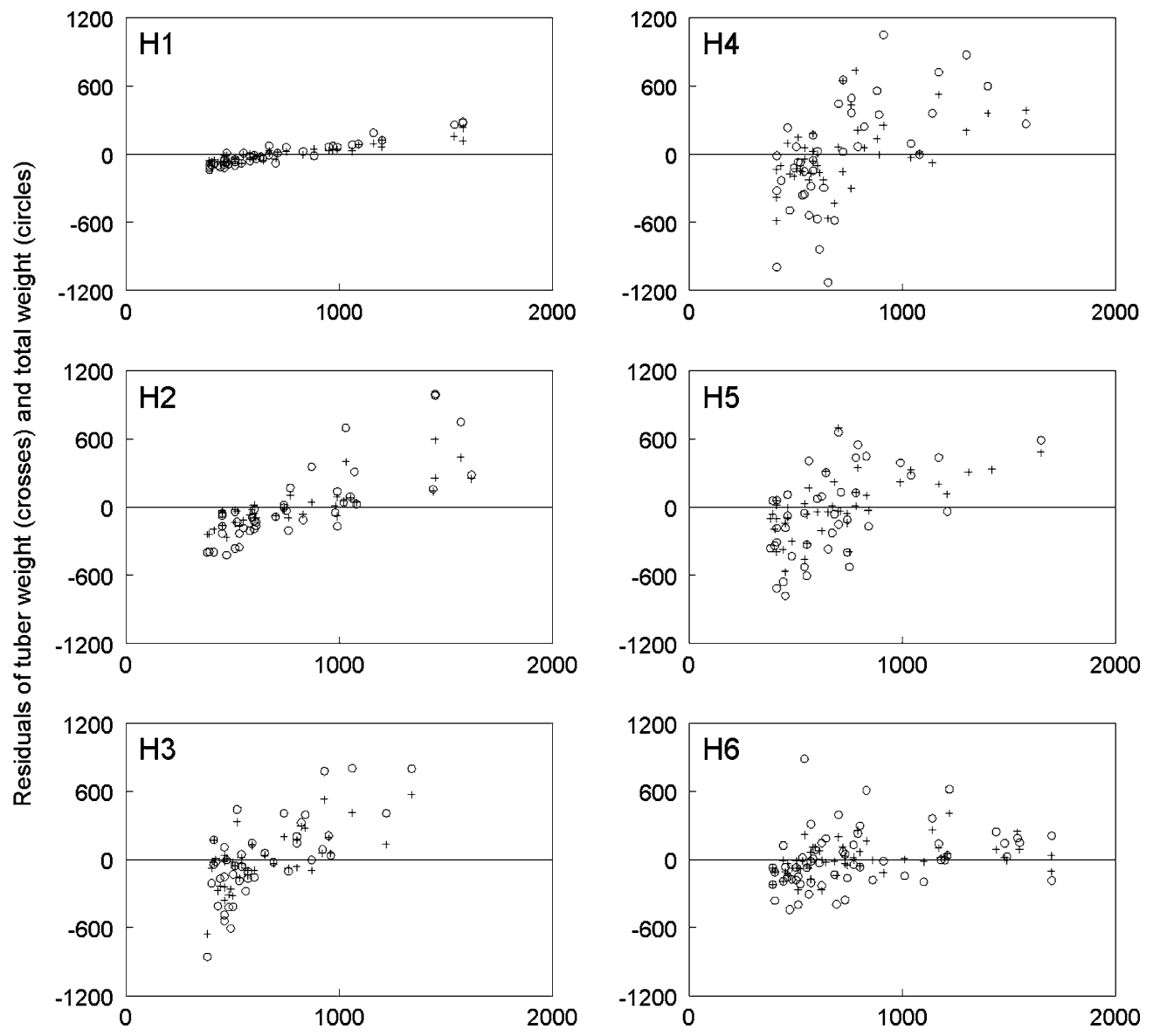

Initial tuber fresh weight (mg)

during times of increased carbohydrate needs, imposed by environmental (e.g., shading, herbivory) or developmental (e.g., leaf display, reproduction) factors (Iwasa and Cohen 1989; Whigham 1990; Zimmerman and Whigham 1992; Rockwood and Lobstein 1994; Iwasa and Kubo 1997; Meloche and Diggle 2003). It is generally assumed that in geophytes, assimilates stored in tubers allow for a fast leaf display at the beginning of the growing period. Nevertheless, we did not record any decrease in tuber dry weight during leaf development. This is in accordance with Wyka's (1999) study on Oxytropis. In contrast to results reported by Wyka (1999), the tuber weight of B. bulbocastanum plants decreased strongly in individuals that showed high biomass investments into flower and seed production. This relationship may point at significant cost of reproduction in our species.

\section{Reproduction}

Even though $B$. bulbocastanum is a perennial species with the ability to flower repeatedly, this species allocated up to $50 \%$ of its total biomass to reproductive structures (including inflorescence-bearing stems, umbels, flowers and seeds). Such an extraordinarily high investment into reproduction is comparable to sexual allocation patterns in monocarpic Apiaceae species (Harper 1977; Abrahamson 1979; Lovett Doust 1980), suggesting that B. bulbocastanum has evolved a growth and survival strategy which includes features of polycarpic perennials (storage) and monocarpic annuals or biennials (high reproductive allocation).

Resource availability had strong effects on reproductive allocation. While nutrient availability was the main determinant of stem growth, flower and seed production was primarily determined by light conditions. In spite of high investments into inflorescencebearing stems, plants subjected to low light conditions allocated only a small fraction of their total biomass to inflorescences and seeds, possibly indicating severe carbon limitations under shaded conditions. This is a remarkable fact considering the presence of a relatively large storage organ throughout the growing season. It indicates that survival takes clear priority over reproduction in case of severe resource shortage, suggesting that $B$. bulbocastanum adopts a tolerancethrough-survival rather than an escape-by-flowering strategy. The high allocation to stems in shaded conditions can be understood as costs of organ preformation and the inability to respond quickly to current light conditions. Under high light conditions seed production 

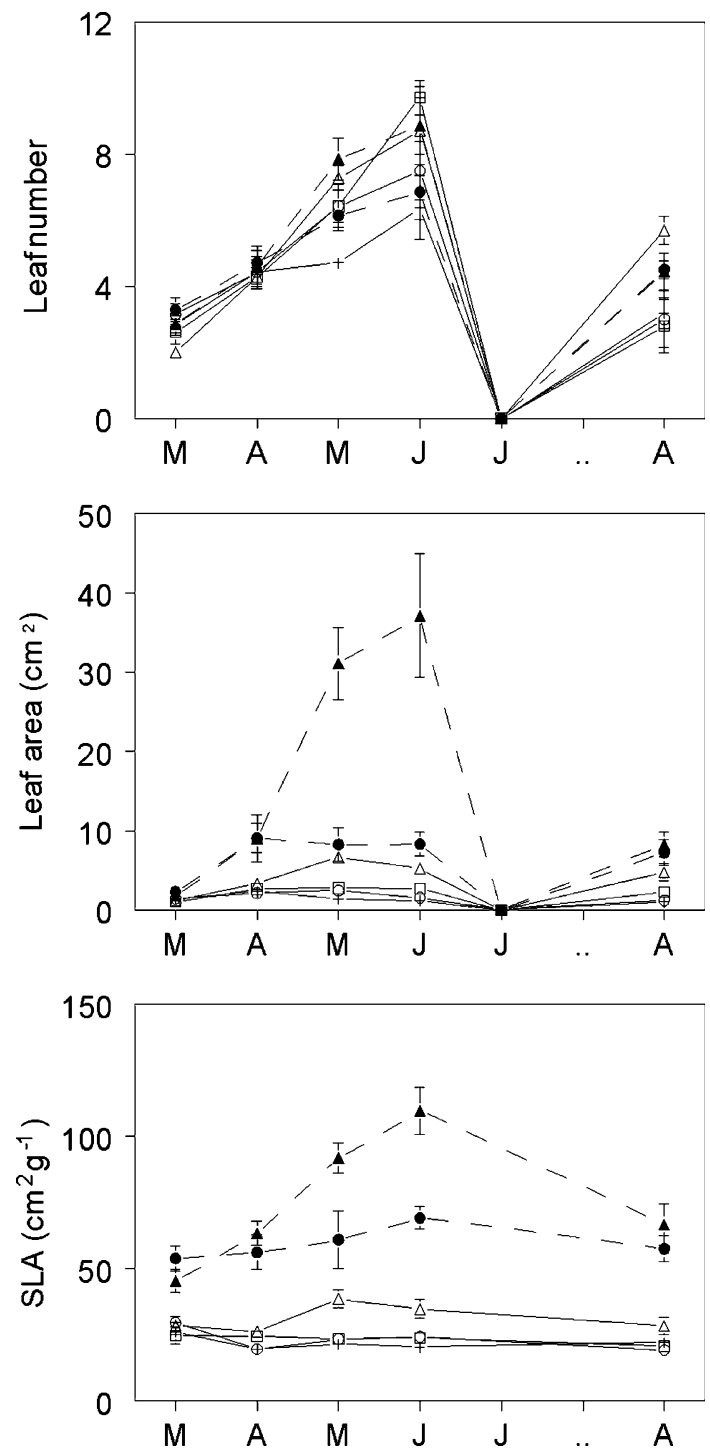

Fig. 3 Effects of light and nutrient availabilities on leaf characteristics throughout the growing period. For significances of the effect of light availability, nutrient availability and harvest time, see Table 1. Symbols used in graphs: triangles N100, squares N50, circles N25, crosses N12. Open symbols, full lines high light, closed symbols, broken lines low light

was associated with high costs in terms of tuber weight decreases, supporting the notion that under favorable growth conditions stored carbohydrates can play an important role in reproductive allocation (Pantis 1993; Othen and Wehrmeyer 2004).

\section{Plasticity to environmental quality}

Our experiment revealed a high plasticity of the total leaf area in shaded plants exposed to high nutrient availability. This response was due to an increased biomass allocation to leaves and to morphological plasticity in leaf structure. In combination these factors resulted in a multiplicative increase of total leaf area in shaded,
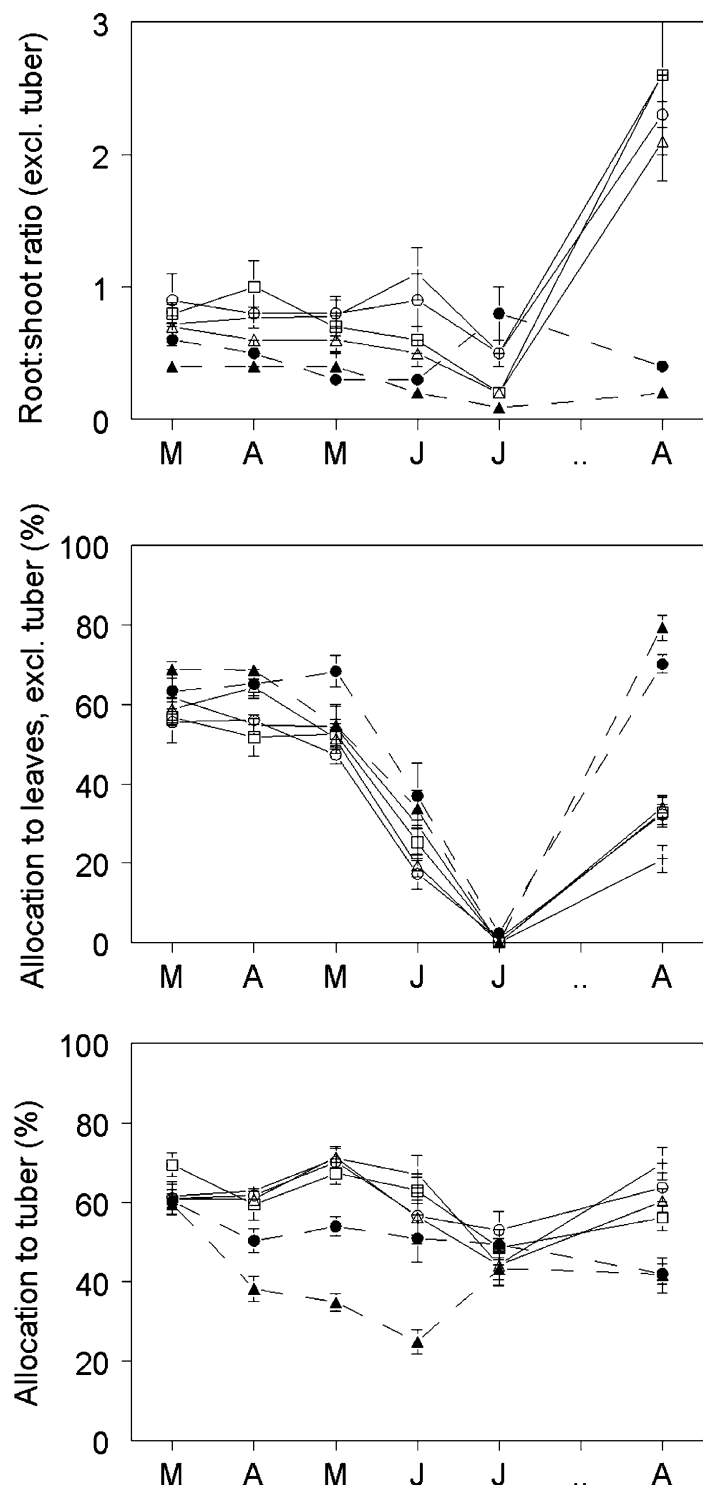

Fig. 4 Seasonal pattern of biomass allocation to roots, leaves and tuber. Symbols used in graphs: triangles N100, squares N50, circles $\mathrm{N} 25$, crosses N12. Open symbols, full lines high light, closed symbols, broken lines low light

fertilized plants. Despite this high degree of plasticity in leaf area, shaded plants in the two nutrient environments did not differ in tuber weight or seed production, indicating that plasticity in leaf traits did not translate into benefits in terms of reproduction (seed production) or survival (tuber biomass). Additional resources gained by the larger leaf area were apparently allocated to other plant structures, such as stems. Since all shaded plants showed a very low investment into inflorescences and seeds, however, this increased allocation to stems was not beneficial in terms of seed output.

Potential effect of preformation on leaf display

B. bulbocastanum is characterized by the preformation of leaves and flowering shoots which allows the species 
to quickly display the leaves in early spring. Organ preformation is a strategy to deal with environments characterized by predictable seasonality, where an unfavorable period is followed by a short period of favorable conditions (Inouye 1986; Wijensinghe and Whigham 1997), within which vegetative and generative development has to be completed. Preformation of organs may not necessarily be favorable in unpredictably fluctuating environments (Geber et al. 1997a, b) as it can strongly constrain the developmental flexibility needed to respond in a plastic way to changes in the environment.

Plants displayed a higher treatment-induced variation in leaf numbers and allocation to leaves in the fourth as compared with the third growing season. Preformation had significant effects on resource uptake and development in the present growing season, while the consequences of the present environments may be manifested mainly in future growing seasons (Geber et al. 1997a; Worley and Harder 1999; Ehrlen and van Groenendael 2001). Our results indicate that organ preformation can limit environmentally induced changes in the growth and biomass allocation pattern. Nevertheless, the leaves were clearly able to functionally change their morphology in accordance with ambient light and nutrient conditions. Leaf structural plasticity may partly compensate for the lack of phenotypic plasticity in leaf numbers due to organ preformation.

\section{Conclusions}

Belowground tubers of ephemeral perennial plants serve several main functions: (1) survival during the unfavorable period in strongly seasonal environments, (2) support of quickly unfolding leaves in early spring, (3) support of the growth of flowering stems and reproduction, (4) long-term adjustment of leaf numbers according to variation in resource availability. The results of our study suggest that the first and the last function may by be far more important for a spring geophyte with organ preformation than the other two. This study has also proved that (a) reproductive allocation is very high under resource-rich conditions, and (b) that survival takes priority over reproduction in case of resource shortage. This shows that organ preformation in such spring geophytes is an effective buffer constraining plastic adjustments to temporal variation in environmental quality. Furthermore, such geophytes employ a consolidation rather than an escape strategy, as investment into the perennating storage organ is prioritized over the use of stored carbohydrates for stimulating costly plastic adjustments to the environment or for enhancing reproduction.

Acknowledgements We thank Fan Zhang for invaluable help during the experiment, and Heinjo During and Josef Stuefer and two anonymous referees for insightful comments on an earlier version of this manuscript.

\section{References}

Abrahamson WG (1979) Patterns of resource allocation in wildflower populations of fields and woods. Am J Bot 66:71-79

Aydelotte AR, Diggle PK (1997) Analysis of developmental preformation in the alpine herb Caltha leptosepala. Am J Bot 84:1646-1657

Beard JS (1983) Ecological control of the vegetation of southwestern Australia: moisture versus nutrients. In: Kruger FJ, et al (eds) Mediterranean-type ecosystems. Springer, Berlin Heidelberg New York, pp 66-73

Billings WD, Mooney HA (1968) The ecology of arctic and alpine plants. Biol Rev 43:481-529

Bobbink R, Willems JH (1987) Increasing dominance of Brachypodium pinnatum (L.) Beauv. in chalk grasslands: a threat to a species-rich ecosystem. Biol Cons 40:301-314

Chapin FS, Schulze ED, Mooney HA (1990) The ecology and economics of storage in plants. Annu Rev Ecol Syst 21:423-477

Diggle PK (1997) Extreme preformation in alpine Polygnonum viviparum: An architectural and developmental analysis. Am J Bot 84:154-169

Ehrlen J, van Groenendael J (2001) Storage and the delayed costs of reproduction in the understorey perennial Lathyrus vernus. $\mathrm{J}$ Ecol 89:237-246

Elemans M (2005) Plant traits in forest understory herbs-a modeling study. PhD thesis, Utrecht University

Geber MA, de Kroon H, Watson MA (1997a) Organ preformation in mayapple as a mechanism for historical effects on demography. J Ecol 85:211-223

Geber MA, Watson MA, de Kroon H (1997b) Organ preformation, development and resource allocation in perennials. In: Bazzaz FA, Grace J (eds) Plant resource allocation. Academic, New York, pp 113-141

Harper JL (1977) Population biology of plants. Academic, London Hegi G (1975) Illustrierte Flora von Mitteleuropa. Band V/2. P.Parey, Berlin

Huber H, Stuefer JF, Willems JH (1996) Environmentally induced carry-over effects on seed production, germination and seedling performance in Bunium bulbocastanum (Apiaceae). Flora 191:353-361

Huber H, Fijan A, During HJ (1998) A comparative study of spacer plasticity in erect and stoloniferous herbs. Oikos 81:576586

Huber H, Whigham DF, O'Neill J (2004) Time of disturbance can change life history decisions in the clonal forest understory herb Uvularia perfoliata. Evol Ecol 18:521-539

Inouye DW (1986) Long-term preformation of leaves and inflorescences by a long-lived perennial monocarp, Frasera speciosa (Gentianaceae). Am J Bot 73:1535-1540

Irmisch T (1854) Beiträge zur vergleichenden Morphologie der Pflanzen I. Abhandlungen der naturforschenden Gesellschaft zu Halle 2:31-80

Iwasa Y, Cohen D (1989) Optimal growth schedule of a perennial plant. Am Nat 133:480-505

Iwasa Y, Kubo T (1997) Optimal storage for recovery after unpredictable disturbances. Evol Ecol 11:41-65

Kawano S (1985) Life history characteristics of temperate woodland plants in Japan. In: White $\mathbf{J}(\mathrm{ed})$ The population structure of vegetation. (W.) Junk, The Hague, pp 515-549

Kleijn D, Treier UA, Müller-Schärer H (2005) The importance of nitrogen and carbohdrate storage for plant growth of the alpine herb Veratrum album. New Phytol 166:565-575

Körner C (2003) Alpine plant life, 2nd edn. Springer, Berlin Heidelberg New York

de Kroon H, Huber H, Stuefer JF, van Groenendael JM (2005) A modular concept of phenotypic plasticity in plants. New Phytol 166:73-82

Lovett Doust J (1980) Experimental manipulation of patterns of resource allocation in the growth cycle and reproduction of Smyrnium olustratum L. Biol J Linn Soc 13:155-166 
Meloche CG, Diggle PK (2003) The pattern of carbon allocation supporting growth of preformed shoot primordia in Acomastylis rossii (Rosaceae). Am J Bot 90:1313-1320

Meusel H, Jaeger E, Rauschert S, Weinert E (1978) Vergleichende Chorologie der zentraleuropaeischen Flora. Band II. Fischer, Jena

Mössler JG (1833) Mösslers Handbuch der Gewächskunde. 1. Band 2. Abteilung 3. Auflage, JF Hammerich, Altona

Onipchenko V (ed) (2004) Alpine vegetation ecology of the western Caucasus. Kluwer, Dordrecht

Orshan G (1989) Plant pheno-morphological studies in Mediterranean type ecosystems. Kluwer, Dordrecht

Othen B, Wehrmeyer A (2004) Seasonal dynamics of non-structural carbohydrates in bulbs \& shoots of the geophyte $\mathrm{Ga}$ lanthus nivalis. Physiol Plant 120:529-536

Packham JR, Harding DJL (1982) Ecology of woodland processes. Edward Arnold, London

Pantis JD (1993) Biomass and nutrient allocation patterns in the Mediterranean geophyte Asphodelus aestivus Brot (Thessaly, Greece). Acta Oecol 14:489-500

Pigliucci M (2001) Phenotypic plasticity: beyond nature and nurture. The Johns Hopkins University Press, Baltimore

Rauh M (1950) Morphologie der Nutzpflanzen. Quelle \& Meyer, Heidelberg

Rockwood LL, Lobstein MB (1994) The effects of experimental defoliation on reproduction in four species of herbaceous perennials from northern Virginia. Castanea 59:41-50

Salisbury EJ (1925) The structure of woodlands. Veroff Geobot Inst Rübel Zürich 3:334-354

Schlichting CD, Pigliucci M (1998) Phenotypic evolution. A reaction norm perspective. Sinauer Associates Inc., Sunderland

Sohn JJ, Policansky D (1977) The costs of reproduction in the mayapple Podophyllum peltatum (Berberidaceae). Ecology 58:1366-1374
Suzuki JI, Stuefer JF (1999) On the ecological and evolutionary significance of storage in clonal plants. Plant Species Biol 14:11-17

von Willert DJ, Eller BM, Werger MJA, Brinckmann E, Ihlenfeldt HD (1992) Life strategies of succulents in deserts. Cambridge University Press, Cambridge

Werger MJA, van Laar EMJM (1985) Seasonal changes in the structure of the herb layer of a deciduous woodland. Flora 176:351-364

Whigham DF (1974) An ecological life-history study of Uvularia perfoliata. Am Midl Nat 91:343-359

Whigham DF (1990) The effects of experimental defoliation on the growth and reproduction of a woodland orchid, Tipularia discolor. Can J Bot 68:1812-1816

Wijensinghe DK, Whigham DF (1997) Cost of producing clonal offspring and the effects of plant size on population dynamics of the woodland herb Uvularia perfoliata (Liliaceae). J Ecol 85:907-919

Willems JH, Bobbink R (1990) Spatial processes in the succession of chalk grassland on old fields in the Netherlands. In: Krahulec F, Agnew AD, Willems JH (eds) Spatial processes in plant communities. SPB Academic Publishing, The Hague, pp 237-249

Worley AC, Harder LD (1999) Consequences of preformation for dynamic resource allocation by a carnivorous herb, Pinguicula vulgaris (Lentibulariaceae). Am J Bot 86:1136-1145

Wyka T (1999) Carbohydrate storage and use in an alpine population of the perennial herb, Oxytropis sericea. Oecologia 120:198-208

Wyka T (2000) Effects of nutrients on growth rate and carbohydrate storage in Oxytropis sericea: A test of the carbon accumulation hypothesis. Int J Plant Sci 161:381-386

Zimmerman JK, Whigham DF (1992) Ecological functions of carbohydrates stored in corms of Tipularia discolor (Orchidaceae). Funct Ecol 6:575-561 